\title{
Delayed Intravitreal Anti-VEGF Therapy for Patients During the COVID-19 Lockdown: An Ethical Endeavor
}

This article was published in the following Dove Press journal: Clinical Ophthalmology

\author{
Mutasem Elfalah (D) \\ Saif Aldeen AIRyalat (iD \\ Mario Damiano Toro (iD) ${ }^{2-4}$ \\ Robert Rejdak ${ }^{4}$ \\ Sandrine Zweifel ${ }^{3}$ \\ Rashed Nazzal (iD ${ }^{5}$ \\ Mohammed Abu-Ameerh' \\ Osama Ababneh' \\ Almutez Gharaibeh ${ }^{\prime}$ \\ Zuhair Sharif ${ }^{\prime}$ \\ Jehad Meqbil ${ }^{\prime}$ \\ Mo'ath AIShawabkeh (iD) \\ Amal Alwreikat ${ }^{6}$ \\ Muawyah Al Bdour' \\ Maysa Al-Hussaini (D) \\ Yacoub A Yousef ${ }^{8}$ \\ 'Department of Special Surgery, Faculty of \\ Medicine, The University of Jordan, Amman, \\ Jordan; ${ }^{2}$ Faculty of Medical Sciences, Collegium \\ Medicum, Cardinal Stefan Wyszyński \\ University, Warsaw, Poland; ${ }^{3}$ Department of \\ Ophthalmology, University Hospital of Zürich, \\ Zürich, Switzerland; ${ }^{4}$ Department of General \\ Ophthalmology, Medical University of Lublin, \\ Lublin, Poland; ${ }^{5}$ Shami Eye Center, Amman, \\ Jordan; ${ }^{6}$ Department of Ophthalmology, Royal \\ Medical Services, Amman, Jordan; ${ }^{7}$ Department \\ of Pathology and Laboratory Medicine, King \\ Hussein Cancer Center, Amman, Jordan \\ ${ }^{8}$ Department of Surgery (Ophthalmology), King \\ Hussein Cancer Center, Amman, Jordan
}

Correspondence: Mutasem Elfalah Department of Special Surgery, Faculty of Medicine, The University of Jordan, Queen Rania St, Amman, I 194I, Jordan Tel +96265355000

Email mutasemrabie@hotmail.com

Mario Damiano Toro

Department of Ophthalmology,

University Hospital of Zürich,

Raemistrasse 100, Zürich, 809I,

Switzerland

Tel +393495158220

Email toro.mario@email.it
Purpose: To assess the impact of Jordanian's Corona Virus Disease (COVID-19) lockdown on visual acuity and macular thickness in patients with macular edema receiving intravitreal injections, and to assess the ethical endeavor of lockdown among serious sight threatening conditions.

Patients and Methods: This retrospective observational study included patients planned for intravitreal injections who did not complete the planned course before the lockdown (ie, before 20th of March 2020). Data included demographics, indication for the intravitreal injection, corrected distance visual acuity (CDVA), and central macular thickness on Optical Coherence Tomography (OCT) before and after the lockdown.

Results: One-hundred and sixty-six eyes of 125 patients were studied, 68 (54.4\%) patients were males, and the mean ( \pm standard deviation, SD) age was $64.79( \pm 9.41)$ years. Mean $( \pm$ SD) duration of delay in the planned injection was $60.97( \pm 24.35)$ days. The change in visual acuity was statistically significant for patients with diabetic macular edema $(p=0.045$ improvement), patients with central retinal vein thrombosis (CRVO) ( $p=0.05$ deterioration), and patients with age-related macular degeneration (AMD) $(\mathrm{p}=0.005$ deterioration). Of interest, delay of more than 2 months and the previous need for 3 or more injections were significant poor prognostic factors for visual outcome for patients with diabetic macular edema $(\mathrm{p}=0.027$ and 0.045$)$.

Conclusion: The impact of delay in the scheduled intravitreal injections resulted in variable outcomes depending on the indication. Triaging the urgency of patients should be based on the indication to support the equity principle of bioethics, where those in need are prioritized against others, depending on potential adverse outcome.

Keywords: COVID-19 lockdown, COVID-19 pandemic, ethics, intravitreal injection, macular edema

\section{Introduction}

The recently emerged viral outbreak of the Severe Acute Respiratory Syndrome Coronavirus 2 (SARS-CoV-2) led to the Corona Virus Disease (COVID-19) Pandemic. This disease was announced as a global pandemic by the World Health Organization on 11th of March 2020. ${ }^{1}$ The pandemic led to several nationwide lockdown decisions throughout the world, accompanied by healthcare bodies' guidelines on how to deal with patients during the pandemic. ${ }^{2}$ Ophthalmology is among the fields where physicians have close contact with patients during examination, and considering the possibility of COVID-19 manifesting as conjunctivitis, 
ophthalmologists might be the first to contact a COVID-19 patient, and several measures are now suggested to protect against infection. $^{2-5}$

Intravitreal injection is the most commonly performed ophthalmic procedure, with the number of injections given yearly having increased 100-folds during the last decade, as patients with different indications are given a significant number of injections yearly. ${ }^{6-9}$ In March 2020, the American Academy of Ophthalmology (AAO) issued a recommended practice guideline urging practicing ophthalmologists to provide care for only "urgent" or "emergent" cases. ${ }^{10}$ The Academy recognized that "urgency" is determined by physician's own judgment, taking into account individual patient medical and social circumstances. While the AAO recommendation left the decision of determining urgency or emergency to the treating physicians, the American Society of Retina Specialists described intravitreal injection therapy as "essential". 11

In Jordan, the first SARS-CoV-2 infected case was registered on the 2nd of March 2020 for a Jordanian citizen coming from Italy. $^{12}$ On 18 March 2020, a nationwide lockdown was announced restricting all movements, including healthcare institutions, with an exemption for emergency departments. The lockdown decision led to a reduction in transport mobility of up to 95\% compared to baseline, where hospital visits were carried out only by ambulances. ${ }^{13}$ These restrictions led to cessation of intravitreal injection administration in Jordan, until 28th of April, where these injections resumed. The decision to discontinue intravitreal injection during the current COVID-19 pandemic in Jordan represented part of a more general decision to suspend all elective and semi-urgent procedures in order to achieve better allocation of the potentially scarce medical resources in this developing country to those who need it the most. ${ }^{14}$ However, the clinical impact of such decision and its ethical implications were not fully considered.

In this study, we aim to assess the impact of Jordan's lockdown on visual acuity and macular thickness in patients receiving intravitreal injection, and their perception about their change in vision during the lockdown period. We will then discuss briefly the ethical consideration of the principle of justice, in particular equity versus equality, in this particular setting.

\section{Patients and Methods}

This was a retrospective observational study that took place at Jordan University Hospital from 20th of April to 1st of July, 2020. The Ophthalmology Department is a tertiary referral center for the management of ocular diseases. This study was conducted in accordance with the Declaration of Helsinki. Ethical approval was granted by the Institutional Review Board (IRB) at Jordan University Hospital, and all patients signed an informed consent prior to participating in the study.

The study included 125 patients who were planned for intravitreal injections for different indications, but were unable to complete the planned intravitreal injections before the lockdown (ie, before 20th of March 2020). At our institution, we adopt a pro re nata (PRN) approach for treating patients with intravitreal injections, where a loading dose of three intravitreal injections is given followed by a monthly follow-up visit. Patients were invited to attend when intravitreal injections resumed. Indications included diabetic macular edema, proliferative diabetic retinopathy (PDR), neovascularization in agerelated macular degeneration (AMD), branch retinal vein occlusion (BRVO), and central retinal vein occlusion (CRVO). Exclusion criteria included patients who refused to participate, and inability to access patients' previous records, mainly due to patients' attending another institution for treatment. For patients who received bilateral injections, an injection was given in the more severely affected eye, and then the other eye received an injection one week later. Although we included both eyes, we interviewed the patient and asked about each eye separately.

When the Department resumed its work, several protective measures were implemented to protect against the infection when intravitreal injections were restarted. These included:

-A phone call to take a brief history about any symptoms or contact with COVID-19positive individuals.

-Upon confirming a no contact history and absence of any COVID-19 related symptoms, the patient was invited for the injection, where a temperature check using a noncontact device before admission to the building was performed;

-Providing two separate theaters in two separate buildings supervised by two separate teams, to prevent overcrowding and allow distancing between patients;

-Limiting the number of injections to 15 during a 4 hours period, where each patient will attend at an allocated time slot to facilitate distancing;

-The patients and ophthalmology team members wore protective surgical masks, noting that the patient's mask 
moved down the nose during cleaning with povidone, draping, and injection administration.

When a patient visits the hospital to resume his/her intravitreal injections, an ophthalmology resident first explains the nature of the study and obtains the informed consent. Data regarding the corrected distance visual acuity (CDVA), slit lamp examination and central macular thickness on Optical Domain Tomography (OCT) before the lockdown were obtained from the electronic medical records (EMR), including hemoglobin A1c within one month of inclusion. Then, a questionnaire was carried out asking about demographic variables, co-morbidities, patients' anxiety and perception regarding their visual acuity change during lockdown, and their trust in the treating physician and in the recent medical institutional decisions and actions during lockdown. The questions about anxiety and trust are straight forward questions with the answer being a scale from 0 (least) to 10 (most). After the questionnaire, the CDVA, measured using a Snellen chart at $6 \mathrm{~m}$, was recorded using the decimal system, then slit lamp and fundus examination was performed. Finally, a new macular thickness OCT was obtained. OCT images before and after the lockdown were obtained using RTVue-100 Fourier-Domain highresolution Optical Coherence Tomography (OCT) from Optovue, Inc., Fremont, CA.

For sub-group analysis, we categorized patients concerning number of previous injections into those who did not yet complete a loading dose (ie, less than 3 injections), and those who took three or more injections before the last treatment plan was decided upon. We also categorized the delay in injection into less and equal to two months and more than two months. For patients with visual acuity less than 0.05 on the decimal system, we measured visual acuity via counting fingers, hand motion, light perception, and no light perception, which were then converted into $0.014,0.005,0.0016$, and 0.0013 , respectively. ${ }^{15}$

\section{Statistical Analysis}

IBM SPSS Statistics for Windows, version 21 (IBM Corp., Armonk, N.Y., USA) was used in our analysis. The mean ( \pm standard deviation, SD) was used to describe continuous variables (eg, age) and count (frequency) to describe other nominal variables (eg, gender). Paired sample $t$-test was used to analyze the change in visual acuity and in macular thickness before and after the lockdown period. After calculating the difference in visual acuity and macular thickness before and after the lockdown period,
Pearson correlation test was performed to analyze the correlation with duration of delay in the planned injections, and with responses of the questionnaire. One-way ANOVA was used to analyze the difference in visual acuity change or macular thickness changes with the indication of injections. A cut-off value of $p \leq 0.05$ was considered statistically significant.

\section{Results}

One hundred and twenty-five patients were included in this study, with a mean $( \pm \mathrm{SD})$ age of $64.79( \pm 9.41)$ years, ranging from 35 to 91 years. Sixty-eight $(54.4 \%)$ males and fifty-seven $(45.6 \%)$ females were included. One hundred and two patients $(81.6 \%)$ had diabetes mellitus with a mean $( \pm \mathrm{SD})$ hemoglobin A1c (HbA1c) of $7.65( \pm 1.34)$, $71(56.8 \%)$ had hypertension, and $31(24.8 \%)$ had ischemic heart disease.

There were 166 eyes, 82 (49.4\%) were bilateral eyes from 41 patients. Eighty-six (51.8\%) were right eyes, and $80(48.2 \%)$ were left eyes. The mean $( \pm \mathrm{SD})$ duration of delay in the planned injection was $60.97( \pm 24.35)$ days (range 29 to 210 days). Table 1 shows the demographic features and the characteristics of the included sample.

Upon analyzing the change in visual acuity and macular thickness, there was improvement in visual acuity for patients with diabetic macular edema and patients with proliferative diabetic retinopathy (PDR), and deterioration in visual acuity for patients with age-related macular degeneration (AMD), branch retinal vein occlusion (BRVO), and central retinal vein occlusion (CRVO). In addition, there was improvement (decrease) in macular edema for all patients except those with CRVO (Table 2 ). The change in visual acuity was statistically significant for patients with macular edema ( $\mathrm{p}=0.045$, improvement), patients with CRVO ( $\mathrm{p}=0.05$, deterioration), and patients with AMD ( $p=0.005$, deterioration). No statistically significant difference in macular thickness was noticed for all indications $(p=0.128)$. No statistically significant correlation was found between change in visual acuity or macular thickness and duration of delay ( $\mathrm{p}=0.09$ and 0.817 , respectively), gender ( $\mathrm{p}=0.720$ and 0.312 , respectively), or other co-morbidities. According to changes in visual acuity with delay in intravitreal injection, we developed a framework to prioritize patients scheduled for intravitreal injections according to the indication, where patients with the highest expected chance of worsening are prioritized.

We performed a sub-group analysis for DME patients $(n=109)$ to analyze the effect of the duration of delay and 
Table I Characteristics of the Included Sample

\begin{tabular}{|c|c|c|c|c|}
\hline & & Count & $\%$ & $\begin{array}{c}\text { Mean ( } \pm \\
\text { Standard } \\
\text { Deviation) }\end{array}$ \\
\hline Laterality & $\begin{array}{l}\text { Right } \\
\text { Left }\end{array}$ & $\begin{array}{l}86 \\
80\end{array}$ & $\begin{array}{l}51.8 \% \\
48.2 \%\end{array}$ & \\
\hline Diagnosis & $\begin{array}{l}\text { AMD } \\
\text { DME } \\
\text { BRVO } \\
\text { CRVO } \\
\text { PDR } \\
\text { Other }\end{array}$ & $\begin{array}{c}22 \\
109 \\
10 \\
4 \\
19 \\
2\end{array}$ & $\begin{array}{c}13.3 \% \\
65.7 \% \\
6.0 \% \\
2.4 \% \\
11.4 \% \\
1.2 \%\end{array}$ & \\
\hline Injection type & $\begin{array}{c}\text { bevacizumab } \\
\text { Ranibizumab } \\
\text { Aflibercept } \\
\text { Triamcinolone }\end{array}$ & $\begin{array}{c}81 \\
35 \\
49 \\
1\end{array}$ & $\begin{array}{c}48.8 \% \\
21.1 \% \\
29.5 \% \\
0.6 \%\end{array}$ & \\
\hline \multicolumn{4}{|l|}{ Total injections } & $\begin{array}{c}4.48 \\
( \pm 4.54)\end{array}$ \\
\hline $\begin{array}{l}\text { Frequency of } \\
\text { injections } \\
\text { completed } \\
\text { before lockdown } \\
\text { Injections } \\
\text { completed from } \\
\text { last scheduled } \\
\text { decision before } \\
\text { lockdown }\end{array}$ & $\begin{array}{l}1.00 \\
2.00 \\
3.00 \\
4.00 \\
6.00 \\
0.00 \\
1.00 \\
2.00\end{array}$ & $\begin{array}{c}13 \\
9 \\
141 \\
1 \\
2 \\
63 \\
63 \\
39\end{array}$ & $\begin{array}{c}7.8 \% \\
5.4 \% \\
84.9 \% \\
0.6 \% \\
1.2 \% \\
38.0 \% \\
38.0 \% \\
23.5 \% \\
\\
0.6 \%\end{array}$ & \\
\hline \multicolumn{4}{|l|}{ Duration lateness } & $\begin{array}{c}60.97 \\
( \pm 24.35)\end{array}$ \\
\hline $\begin{array}{l}\text { Previous steroid } \\
\text { injection }\end{array}$ & $\begin{array}{l}\text { Yes } \\
\text { No }\end{array}$ & $\begin{array}{l}15 \\
151\end{array}$ & $\begin{array}{l}9.0 \% \\
91.0 \%\end{array}$ & \\
\hline \multicolumn{4}{|l|}{ Visual acuity before } & $\begin{array}{c}0.30( \pm \\
0.24)\end{array}$ \\
\hline \multicolumn{4}{|l|}{ Visual acuity after } & $\begin{array}{c}0.32 \\
( \pm 0.26)\end{array}$ \\
\hline \multicolumn{4}{|c|}{ Macular thickness $(\mu \mathrm{m})$ before } & $\begin{array}{c}398.31 \\
( \pm \mid 38.21)\end{array}$ \\
\hline \multicolumn{4}{|c|}{ Macular thickness $(\mu \mathrm{m})$ after } & $\begin{array}{c}370.04 \\
( \pm \mid 50.33)\end{array}$ \\
\hline
\end{tabular}

Abbreviations: AMD, age-related macular degeneration; DME, diabetic macular edema; BRVO, branch retinal vein occlusion; CRVO, central retinal vein occlusion; PDR, proliferative diabetic retinopathy.

the number of previous injections on the change in CDVA and OCT macular thickness (Table 3). Patients who had a delay of more than 2 months had significantly worse visual acuity compared to those with less than 2 months delay $(p=0.027$, mean difference 0.070 , 95\% CI 0.008 -0.13 ), and they had less improvement in macular thickness $(\mathrm{p}=0.047)$. Moreover, patients who had previously received 3 or more injections had significantly worse visual acuity compared to those who took less than 3 injections $(p=0.045$, mean difference $0.068,95 \%$ CI $0.002-0.13)$.

Upon analyzing the overall change in macular edema, irrespective to indication, we found a significant change in macular thickness that occurred during the delay $(\mathrm{p}=$ $0.041)$; with the mean $( \pm \mathrm{SD})$ macular thickness before commencement of injection being $401.70 \mu \mathrm{m}( \pm 146.64)$ compared to $369.09 \mu \mathrm{m}( \pm 156.14)$, with a mean difference of $32.62 \mu \mathrm{m}$ (95\% CI 1.35-63.89). No significant difference was observed in overall changes in visual acuity $(\mathrm{p}=$ $0.294)$, as the mean difference was 0.014 (95\% CI 0.04-0.012).

As for complications suffered by patients enrolled in this study, four patients had an incidence of vitreous hemorrhage, and two patients had neovascularization of the iris.

Table 4 shows the answers on the subjective assessment. The majority of patients rated their vision from very poor to fair $128(77.1 \%)$. There was a significant positive correlation between patient's reported worsening of vision and duration of delay $(\mathrm{p}=0.001$, Pearson coefficient $=$ 0.258 ), although no significant correlation was found between patients' reported worsening of vision and the objectively measured change in visual acuity $(p=0.078)$.

\section{Discussion}

In our analysis of the outcomes of delayed intravitreal injection during COVID-19 lockdown, we observed variable outcomes according to the indication of injection, where the change in visual acuity was statistically significant for patients with macular edema ( $\mathrm{p}=0.045$, improvement), patients with CRVO ( $\mathrm{p}=0.05$, deterioration), and patients with AMD $(p=0.005$, deterioration). Since the beginning of the COVID-19 pandemic, several ophthalmologists published their experiences and proposed strategies in dealing with patients in need for intravitreal injections during the pandemic. ${ }^{10,11,16-18}$ Almost all concur that the number of injections given to a patient during the pandemic is less than intended. ${ }^{19}$ Furthermore, Romano et al showed that the COVID-19 related lockdown in Italy led to a delay in delivery of intravitreal injections to neovascular age-related macular degeneration 
Table 2 Comparison Between Different Indications in Regard to Visual Acuity and Macular Thickness Change (After - Before) During the Delay Caused by COVID-19 Lockdown

\begin{tabular}{|c|c|c|c|c|c|c|}
\hline & & \multirow[t]{2}{*}{$\mathbf{N}$} & \multicolumn{2}{|c|}{ Visual Acuity Difference } & \multicolumn{2}{|c|}{ Macular Thickness Difference $(\mu \mathrm{m})$} \\
\hline & & & Mean & Std. Deviation & Mean & Std. Deviation \\
\hline \multirow[t]{7}{*}{ Diagnosis } & AMD & 22 & -0.04 & 0.12 & -13.29 & 195.98 \\
\hline & DME & 109 & 0.02 & 0.18 & -50.91 & 132.80 \\
\hline & BRVO & 10 & -0.03 & 0.17 & -22.67 & 282.30 \\
\hline & CRVO & 4 & -0.09 & 0.14 & 217.00 & 174.94 \\
\hline & PDR & 19 & 0.11 & 0.18 & -37.06 & 131.74 \\
\hline & Other & 2 & -0.10 & 0.14 & -115.00 & - \\
\hline & Total & 166 & 0.01 & 0.17 & -32.62 & 161.58 \\
\hline
\end{tabular}

Abbreviations: AMD, age-related macular degeneration; DME, diabetic macular edema; BRVO, branch retinal vein occlusion; CRVO, central retinal vein occlusion; PDR, proliferative diabetic retinopathy.

Table 3 Subgroup Analysis for Diabetic Macular Edema Patients to Analyze the Effect of the Duration of Delay and the Number of Previous Injections on the Change in VA and OCT Macular Thickness

\begin{tabular}{|c|c|c|c|c|c|c|c|}
\hline & & \multicolumn{2}{|r|}{ Change in VA } & \multirow[b]{2}{*}{ p value } & \multicolumn{2}{|c|}{ Change in Macular Thickness $(\mu \mathrm{m})$} & \multirow[b]{2}{*}{ p value } \\
\hline & & Mean & Standard Deviation & & Mean & Standard Deviation & \\
\hline \multirow[t]{2}{*}{ Previous injections } & $<3$ & 0.05 & 0.16 & 0.045 & -56.52 & 107.70 & 0.734 \\
\hline & 3 and more & -.02 & 0.19 & & -44.48 & 158.73 & \\
\hline \multirow[t]{2}{*}{ Duration of delay } & I-2 months & 0.06 & 0.15 & 0.027 & -66.08 & 147.24 & 0.0472 \\
\hline & $>2$ months & -.01 & 0.16 & & -40.23 & 122.44 & \\
\hline
\end{tabular}

Abbreviation: VA, visual acuity.

Table 4 Answers of the Patient-Reported Questionnaire

\begin{tabular}{|l|l|l|l|l|l|l|}
\hline \multicolumn{2}{|l|}{} & Count & $\%$ & Median & Minimum & Maximum \\
\hline Eyesight using both eyes & Excellent & 4 & $2.4 \%$ & & \\
& Good & 34 & $20.5 \%$ & & \\
& Fair & 73 & $44.0 \%$ & & \\
& Poor & 47 & $28.3 \%$ & & \\
& Very poor & 8 & $4.8 \%$ & & \\
\hline & Blind & 0 & $0.0 \%$ & & 0.00 & 10.00 \\
\hline Worsening of vision during lockdown & & & 1.00 & 0.00 & 10.00 \\
\hline Anxiety due to lockdown delay in injections & & 3.00 & 1.00 & 10.00 \\
\hline
\end{tabular}

patients, which led to higher frequency of complications in this patient group compared to before lockdown. ${ }^{20}$ In this study, most of the patients had diabetic macular edema. The impact of delayed injection was highly variable depending on multiple factors including indication for injection, delay to get injection, number of injections received before the study, and other factors. Patients with CRVO, patients with AMD, and patients with diabetic macular edema that mandated three or more injections had a significant deterioration in visual acuity and macular edema after the delayed injection. Despite the need for further studies, we suggest that ophthalmologists should not postpone the provision of intravitreal injection services for this group of patients for more than 2 months even amid the COVID-19 lockdown and should treat this particular group of patients as emergency cases in order to 
avoid deterioration in visual acuity. Moreover, it appears that less than 2 months delay in injection can be well tolerated and compensated for. Ethically, triaging the urgency of patients should be based on the indication to support the equity against equality, where those in need are prioritized against others, depending on the urgency and potential adverse outcomes. $^{21}$

Several authors have discussed the ethical impact of the pandemic on delivering treatments to patients in need since the beginning of the COVID-19 outbreak. $^{22,23}$ Concerns regarding delivering care to cancer patients were the most commonly addressed. ${ }^{24}$ Cancer patients are usually immunocompromised and at higher risk of adverse outcomes associated with COVID-19 infection. ${ }^{25}$ In addition, the disruption of the treatment plan that is usually decided on at the inception of the diagnosis might result in progression, recurrence and up-staging. These concerns led to the adoption of a framework to prioritize treatment delivery for cases; priority should be based on the probability of mortality and morbidity; high mortality and morbidity due to treatment delay should be given priority over those with a lower probability of morbidity and mortality where delay will not affect the outcome. ${ }^{25}$ A similar framework can be adopted for patients receiving intravitreal injections suffering from sight threatening conditions, especially when the available resources are limited precluding the accommodation of all patients (Figure 1).

Over the last few months, the clinical impact of delaying intravitreal injections in patients with neovascular AMD was the most widely studied. A UK study to estimate the reduction in neovascular AMD referral and the corresponding increase in poor vision if there was a 3-months delay in treatment showed a $72 \%$ reduction

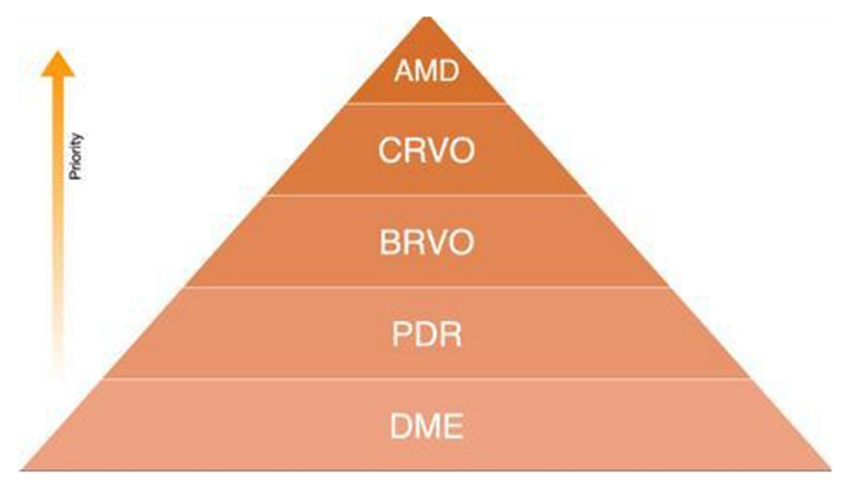

Figure I A framework for prioritizing patients receiving intravitreal injections based on their indications.

Abbreviations: AMD, age-related macular degeneration; DME, diabetic macular edema; BRVO, branch retinal vein occlusion; CRVO, central retinal vein occlusion; PDR, proliferative diabetic retinopathy. in neovascular AMD referrals which might result in an increase in the percentage of patients developing visual acuity $<6 / 60$ from $15.5 \%$ to $23.3 \%{ }^{26}$ In our sub-group analysis; AMD, CRVO, and BRVO patients had worsened due to the delay in injections. Our results are supported by the EXCITE study, where a delay in monthly injections led to poorer outcomes. ${ }^{27}$ In a study comparing the risk of COVID-19 infection and transmission among neovascular AMD patients with visual impairment caused by the neovascular AMD, Boyd et al reported that reduced disease burden from avoiding visual impairment outweighs the expected health-adjusted life-years lost from COVID-19 transmission. ${ }^{28}$ For CRVO, the long-term follow-up in the HORIZON trial previously showed that a delay in followup resulted in worsening of the visual acuity in CRVO but not in BRVO patients, in concordance with our sub-group analysis. ${ }^{29}$ As diabetic macular edema represents the most common indication for intravitreal injection in our cohort, and the most common cause of vision loss from diabetic retinopathy, ${ }^{30}$ we further sub-analyzed diabetic macular edema patients. We reported a worsened outcome in patients who had two or more months delay and received three or more injections compared to those with less than two months delay or those who received less than three injections. These findings are consistent with studies showing variability in response to anti-VEGF therapy among diabetic patients, where the first few anti-VEGF doses are the most effective. ${ }^{31}$ An interesting finding is that despite the subjective feeling reported by patients in regard to worsened CDVA during the lockdown period, the overall CDVA measured objectively was not significantly different $(p=0.294)$.

Our study suggests a link to an important ethical concept; justice and the fairness of allocating limited medical services. Justice, along with autonomy, beneficence, and non-maleficence are the four pillars of an ethical endeavor to patients during clinical care. ${ }^{32}$ These principles are encountered in the daily practice of physicians and other healthcare providers. ${ }^{33}$ Justice is defined as providing a healthcare system that is compatible with the law and rights of the individual, but also is fair and balanced from a societal perspective (the medical portal; Medical Ethics explained: justice). Finding the balance between individual and societal benefits can be troublesome, particularly amid emergencies like the COVID-19 pandemic. In our example, patients should be subdivided, scientifically, into those at high risk of vision deterioration if injections were not administered on time, and those at low risk of vision 
deterioration with delay. In this particular example, delaying the injection has resulted in an inferior outcome to CRVO and neovascular AMD and variable outcomes in diabetic patients. However, the delay in injections probably did provide benefit in the form of reduction of disease transmission to society due to the imposed lockdown.

Sight is considered one of the five senses, which when compromised might negatively affect the quality of life of individuals. Similar to prioritizing treatment to cancer patients during total lockdowns, practicing evidencebased medicine would help deliver care to those who need it the most and allows for ethical prioritization and allocation of resources. ${ }^{34}$ We could argue that, based on our findings, CRVO, neovascular AMD, and patients with diabetic macular edema who required more than three injections should be prioritized when planning the delivery of intravitreal injections during total lockdowns. By tailoring the treatment to those in most need, equity can be considered the ethical value that support the decisionmaking by the treating physician.

Diabetic retinopathy is one of the most common causes of blindness worldwide. $^{30}$ Poorly controlled diabetes remains the major contributor of diabetic retinopathy progression. Patients with uncontrolled diabetes are also more susceptible to infections, including viruses. ${ }^{35}$ This imposes a dilemma, where protecting patients against infections by delaying their appointments might lead to a delay in diabetic retinopathy treatment. While several reports, ${ }^{19}$ including ours, showed that delivering treatment in wellcontrolled conditions will not lead to infection contraction, this should be further studied in the future. Policy makers should bear into account the vision-related morbidities related to any delay in intravitreal injections, particularly for CRVO and neovascular AMD, and their treatment should be continued under well-controlled conditions to also prevent any spread of infection.

The main limitation in our study was the short followup period, where the long-term impact of the lockdown on patients' visual outcomes is yet to be unraveled. Moreover, the small number of patients in each subgroup may hinder the generalizability of our sub-group analysis. The small number also did not allow us to analyze the difference between each type of injection and the outcome.

While retina and its diseases are the major topics where high-quality evidence and randomized controlled trials present, ${ }^{36}$ we believe our study can help policymakers in the decision making, patient prioritization and allocation of resources during times of crises and lockdowns and, in this particular example, how to prioritize patients who should be receiving intravitreal injections.

\section{Conclusion}

The present study was conducted on a small Jordanian cohort of patients with various eye conditions requiring intravitreal injections, who encountered a delay due to the recent COVID-19 pandemic lockdown in Jordan. The delay in the scheduled intravitreal injections resulted in negative variable outcomes depending on the indication of injection. We recommend that triaging the urgency of patients based on the indication of intravitreal injection might be a safe approach in potential future lockdowns and emergencies. Priority should be given to patients who are expected to deteriorate due to any delay. In diabetic patients receiving intravitreal injections, a delay of more than 2 months should be avoided. In this particular setting, equity and not equality should refurbish.

\section{Acknowledgments}

The authors thank all the patients for their participation in this study. Authors are thankful to the Foundation to Support the Development of Ophthalmology, Lublin, Poland, for the technical support during the publication of the results. The Foundation had no role in the design of the study; in the collection, analyses, or interpretation of data; in the writing of the manuscript, or in the decision to publish the results.

\section{Author Contributions}

All authors contributed to data analysis, drafting or revising the article, have agreed on the journal to which the article will be submitted, gave final approval of the version to be published, and agree to be accountable for all aspects of the work.

\section{Funding}

This research received no external funding.

\section{Disclosure}

Dr Sandrine Zweifel reports grants, personal fees from Bayer Healthcare Pharmaceuticals, grants, personal fees from Novartis Pharma AG, and personal fees from Roche Diagnostics, outside the submitted work. The authors report no other conflicts of interest in this work. 


\section{References}

1. WHO Director-General's opening remarks at the media briefing on COVID-19-11 March 2020 [Internet]. Available from: https://www. who.int/dg/speeches/detail/who-director-general-s-opening-remarksat-the-media-briefing-on-covid-19-11-march-2020. Accessed Jun 19, 2020

2. Pei X, Jiao X, Lu D, Qi D, Huang S. How to face COVID-19 in ophthalmology practice medical hypothesis, discovery \& innovation in ophthalmology. Available from: http://mehdijournal.com/index. php/mehdiophthalmol/article/view/830. Accessed January 29, 2021.

3. $\mathrm{Hu} \mathrm{VH}$, Watts E, Burton M, et al. Protecting yourself and your patients from COVID-19 in eye care. Community Eye Health. 2020;33(108):S1-6.

4. Tognetto D, Brézin AP, Cummings AB, et al. Rethinking elective cataract surgery diagnostics, assessments, and tools after the COVID-19 pandemic experience and beyond: insights from the EUROCOVCAT GROUP. DIAGNOSTICS (Basel). Diagnostics. 2020;10(12):E1035. doi:10.3390/diagnostics10121035

5. Ferrara M, Romano V, Steel DH, et al. Reshaping ophthalmology training after COVID-19 pandemic. Eye. 2020;1:1-9.

6. Jørstad ØK, Steffensen LA, Eriksen K, Bragadóttir R, Moe MC. Thirteen years of intravitreal anti-vascular endothelial growth factor therapy: the promises and burdens of a paradigm shift told from the perspective of the largest retina service in Norway. Acta Ophthalmol. 2020;98(8):774-779.

7. Plyukhova AA, Budzinskaya MV, Starostin KM, et al. Comparative Safety of Bevacizumab, Ranibizumab, and Aflibercept for Treatment of Neovascular Age-Related Macular Degeneration (AMD): A Systematic Review and Network Meta-Analysis of Direct Comparative Studies. J Clin Med. 2020;189(5):1522. doi:10.3390/ jcm9051522

8. Reibaldi M, Russo A, Avitabile T, et al. Treatment of persistent serous retinal detachment in Vogt-Koyanagi-Harada syndrome with intravitreal bevacizumab during the systemic steroid treatment. Retina. 2014;34(3):490-6. doi:10.1097/IAE.0b013e3182a0e446

9. Yousef YA, ElRimawi AH, Nazzal RM, et al. Coats' disease: characteristics, management, outcome, and scleral external drainage with anterior chamber maintainer for stage $3 \mathrm{~b}$ disease. Medicine (Baltimore). 2020;99(16):e19623. doi:10.1097/ MD.0000000000019623

10. Recommendations for urgent and nonurgent patient care [Internet]. Available from: https://www.aao.org/headline/new-recommendations -urgent-nonurgent-patient-care. Accessed Jun 19, 2020

11. American Society of Retina Specialists (ASRS) member alert regarding the COVID-19 pandemic [Internet]. Available from: https://www. asrs.org/practice/asrs-member-alert-regarding-covid-19-pandemic. Accessed Jun 19, 2020.

12. Al-Tammemi AB. The battle against COVID-19 in Jordan: an early overview of the Jordanian experience. Front Public Health. 2020;8.

13. COVID-19 community mobility report: Jordan. [Internet]. Google; [cited Jun 19, 2020]. Available from: https://www.gstatic.com/ covid19/mobility/2020-04-11_JO_Mobility_Report_en.pdf. Accessed January 29, 2021.

14. Kramer JB, Brown DE, Kopar PK. Ethics in the time of coronavirus: recommendations in the COVID-19 Pandemic. J Am Coll Surg. 2020;230(6):1114-1118. doi:10.1016/j.jamcollsurg.2020.04.004

15. Schulze-Bonsel K, Feltgen N, Burau H, Hansen L, Bach M. Visual acuities "hand motion" and "counting fingers" can be quantified with the Freiburg visual acuity test. Invest Ophthalmol Vis Sci. 2006;47 (3):1236-1240. doi:10.1167/iovs.05-0981

16. Antaki F, Dirani A. Treating neovascular age-related macular degeneration in the era of COVID-19. Graefes Arch Clin Exp Ophthalmol. 2020;1-3.
17. Corradetti G, Corvi F, Nguyen TV, Sadda SR Management of neovascular age-related macular degeneration during the COVID-19 pandemia. Ophthalmol Retina. doi: 10.1016/j.oret.2020.05.015

18. Colantuono D, Miere A, Semoun O, Amoroso F, Souied EH. AMD management during the COVID-19 Pandemic. Acta Ophthalmol. 2020;98. doi:10.1111/aos.14469

19. Shmueli O, Chowers I, Levy J. Current safety preferences for intravitreal injection during COVID-19 pandemic. Eye. 2020;34 (7):1165-1167. doi:10.1038/s41433-020-0925-x

20. Romano F, Monteduro D, Airaldi M, et al. Increased number of submacular hemorrhages as a consequence of coronavirus disease 2019 lockdown. Ophthalmol Retina. 2020;4(12):1209-1210. doi:10.1016/j.oret.2020.06.027

21. Ghanbari V, Ardalan A, Zareiyan A, Nejati A, Hanfling D, Bagheri A. Ethical prioritization of patients during disaster triage: a systematic review of current evidence. Int Emerg Nurs. 2019;1 (43):126-132.

22. Toro MD, Brézin AP, Burdon $\mathrm{M}$, et al. Early impact of COVID-19 outbreak on eye care: insights from EUROCOVCAT group. Eur J Ophthalmol. 2020;31:1120672120960339. doi:10.1177/1120672120960339

23. Toro M, Choragiewicz T, Posarelli C, Figus M, Rejdak R. European COVID-19 cataract group (\#EUROCOVCAT).Early impact of COVID-19 outbreak on the availability of cornea donors: warnings and recommendations. Clin Ophthalmol. 2020;14:2879-2882. doi:10.2147/OPTH.S260960

24. Wu S, Zheng D, Liu Y, Hu D, Wei W, Han G Radiation therapy care during a major outbreak of COVID-19 in Wuhan. Adv Radiat Oncol. 2020. [cited 2020]; Available from: https://www.ncbi.nlm.nih.gov/ pmc/articles/PMC7270882/.

25. Hanna TP, Evans GA, Booth CM. Cancer, COVID-19 and the precautionary principle: prioritizing treatment during a global pandemic. Nat Rev Clin Oncol. 2020;17(5):268-270. doi:10.1038/s41571-0200362-6

26. Thomas DS, Warwick A, Olvera-Barrios A, et al. Estimating excess visual loss in people with neovascular age-related macular degeneration during the COVID-19 pandemic. medRxiv. 2020.

27. Schmidt-Erfurth U, Eldem B, Guymer R, et al. Efficacy and safety of monthly versus quarterly ranibizumab treatment in neovascular age-related macular degeneration: the EXCITE study. Ophthalmology. 2011;118(5):831-839. doi:10.1016/j. ophtha.2010.09.004

28. Boyd MJ, Scott DAR, Squirrell DM, Wilson GA. How urgent do intravitreal anti-VEGF injections need to be to justify the risk of transmitting COVID-19? Proof-of-concept calculations to determine the Health Adjusted Life-Year (HALY) trade-off. medRxiv. 2020;4.

29. Heier JS, Campochiaro PA, Yau L, et al. Ranibizumab for macular edema due to retinal vein occlusions: long-term follow-up in the HORIZON Trial. Ophthalmology. 2012;119(4):802-809.

30. Lee R, Wong TY, Sabanayagam C. Epidemiology of diabetic retinopathy, diabetic macular edema and related vision loss. Eye Vis

31. Apte RS. What is chronic or persistent diabetic macular edema and how should it be treated? JAMA Ophthalmol. 2016;134(3):285-286. doi:10.1001/jamaophthalmol.2015.5469

32. Beauchamp TL, Childress JF. Principles of Biomedical Ethics. Aufl New York: Oxford; 2013:7.

33. Ebbesen M, Pedersen BD. Empirical investigation of the ethical reasoning of physicians and molecular biologists - the importance of the four principles of biomedical ethics. Philos Ethics Humanit Med. 2007;2(1):23. doi:10.1186/1747-5341-2-23

34. Al-Tabba' A, Al-Hussaini M, Mansour R, Sultan H, Abdel-Razeq H, Mansour A. Ethical considerations for treating cancer patients during the SARS-CoV-2 virus crisis: to treat or not to treat? A literature review and perspective from a cancer center in low-middle income country. Front Med 
35. Casqueiro J, Casqueiro J, Alves C. Infections in patients with diabetes mellitus: a review of pathogenesis. Indian J Endocrinol Metab. 2012;16(Supp11):S27-36. doi:10.4103/2230-8210.94253
36. AlRyalat SA, Abukahel A, Elubous KA. Randomized controlled trials in ophthalmology: a bibliometric study. F1000Research. 2019;4(8):1718. doi:10.12688/f1000research.20673.1

\section{Publish your work in this journal}

Clinical Ophthalmology is an international, peer-reviewed journal covering all subspecialties within ophthalmology. Key topics include: Optometry; Visual science; Pharmacology and drug therapy in eye diseases; Basic Sciences; Primary and Secondary eye care; Patient Safety and Quality of Care Improvements. This journal is indexed on PubMed

Submit your manuscript here: https://www.dovepress.com/clinical-ophthalmology-journal
Central and CAS, and is the official journal of The Society of Clinical Ophthalmology (SCO). The manuscript management system is completely online and includes a very quick and fair peer-review system, which is all easy to use. Visit http://www.dovepress.com/ testimonials.php to read real quotes from published authors. 